\title{
EU Framework Programme for Research \& Innovation contribution to the Circular Economy components'
}

\section{VASILE N. POPA}

National Defense University

\section{LUMINITA I. POPA}

Transilvania University of Brasov: Universitatea Transilvania din Brasov

Anca N. IUGA (BUTNARIU) ( $\square$ anca.iuga@unitbv.ro)

Transilvania University of Brasov: Universitatea Transilvania din Brasov https://orcid.org/0000-00015174-4307

\section{Research}

Keywords: Circular Economy Index, Policy and regulations, Funding policy, Performance indicator

Posted Date: February 7th, 2022

DOI: https://doi.org/10.21203/rs.3.rs-1299315/v1

License: (a) (1) This work is licensed under a Creative Commons Attribution 4.0 International License. Read Full License 
EU Framework Programme for Research \& Innovation contribution to the Circular Economy components'

Vasile N. POPA ${ }^{1}$, Luminita I. POPA ${ }^{2}$, Anca N. IUGA (BUTNARIU) ${ }^{* 3}$

*Correspondence: anca.iuga@unitbv.ro

${ }^{3}$ Transilvania University of Brasov, Postdoctoral studies, B-dul Eroilor nr. 29, Brasov, 500036, Romania Full list of author information is available at the end of the article

\begin{abstract}
Background: The European Union governance for sustainability is presented within a Horizon 2020 project called "Science with and for Society (SwafS)" which is built around five strategic orientations. SwafS projects are expected to support a lot of UN Sustainable Development Goals.

In order to help the European Union countries in improving their R\&D systems, the European Commission's Directorate for R\&D established an appropriate mechanism for the Horizon 2020 program policies, designed to increase the level of participation in projects, improving implementation and evaluation of research and development policies (UEFISCDI, Specific Support to Romania, 2017). The main purpose of this paper was focused to apply a multicriterial method to analyze the contribution of EU Framework Programme for Research \& Innovation policies to the Circular Economy components, according with European Union policy and regulations.

Results: Using a multi-criteria method we were calculating the "Aggregation coefficient" AcHP $\left(\mathrm{A}_{\mathrm{cj}}\right)$ and the Circular Economy Performance Index PI $\mathrm{IE}_{\mathrm{CE}}$ which represent the complex contributions of Horizon 2020 projects' parts on circular economy components.

Conclusion: The novelty of this study lies in our proposal that the Performance Index of the circular economy PIce to be used as a standard of the European Commission when is evaluating the efficiency of the participation of EU and non-EU states in accessing European Funds. This is an interdisciplinary research on the relevance of policies and regulations on circular economy issues, using EU Framework Programme for Research \& Innovation as a model and also the interactions among these issues
\end{abstract}

\title{
KEYWORDS:
}

Circular Economy Index; Policy and regulations; Funding policy; Performance indicator

Abbreviations list for EU Framework Programme for Research \& Innovation Horizon 2020 components

$\begin{array}{ll}\text { Excellent Science } & \text { ES } \\ \text { Industrial Leadership } & \text { IL } \\ \text { Societal Challenges } & \text { SC } \\ \text { European Research Council } & \text { ERC } \\ \text { Future and Emerging Technologies } & \text { FET } \\ \text { Marie Sklodowska Curie Actions } & \text { MSCA } \\ \text { Research Infrastructures } & \text { RI } \\ \text { Leadership in Enabling Industrial Technologies } & \text { LEIT } \\ \text { Access to Risk Finance } & \text { ARF } \\ \text { Innovation in SMEs } & \text { ISME } \\ \text { Health, Demographic Change and Wellbeing } & \text { HDCW } \\ \text { Food Security, Sustainable Agriculture and Forestry, Marine and Maritime and Inland } & \text { FSSAF } \\ \text { Water Research } & \\ \text { Secure, Clean and Efficient Energy } & \text { SCEE } \\ \text { Smart, Green and Integrated Transport } & \text { SGIT } \\ \text { Climate Action, Environment, Resource Efficiency and Raw Materials } & \text { CAERE } \\ \text { Europe in a Changing World - Inclusive, Innovative and Reflective Societies } & \text { ECWII } \\ \text { Secure Societies - Protecting Freedom and Security of Europe and its Citizens } & \text { SSPFS } \\ \text { Spreading Excellence and Widening Participation } & \text { SEWP } \\ \text { Science With and For Society (SwafS) } & \text { SWFS } \\ \text { European Institute of Innovation \& Technology } & \text { EIIT } \\ \text { Joint Research Centre } & \text { JRC } \\ \text { *Except: Others+ Euratom } & \text { EOE }\end{array}$




\subsection{Introduction}

This paper makes significant contribution to European Union Framework Programs policy and regulations and opens up new direction for European Commision experts to explore new and alternative way of using very comprehensive data set for the EU's and non EU's states.

Klakegg et al., 2009 (Klakegg \& Williams, 2009) concluded that European Commision public governance for EU projects is an institutionally established public system that has clearly set the processes and rules to ensure that projects will be completed in accordance with these rules

The modalities of developing major projects for the supply of goods and services are very well described by Flyvbjerg, 2014 (Flyvbjerg, B, 2014). According to Maude Brunet et al. (2016), the governments are the most important public actors for national key projects, often as holder or originator. Consequently, in each country the political class must make clear decisions to carry out these projects (Brunet\& Aubry 2016).

The European Commission adopted its proposal for the eighth Framework Programme (FP), named Horizon 2020, in November 2011 (Reillon, V., 2015 ). In 2013 the European Commission adopted a budget of 77 billion euros for for the Horizon 2020 program.

The mid-term evaluation presented by the Commission in May 2017 confirmed that EU Framework Programme for Research \& Innovation Horizon 2020 was outstanding and that its efficiency was higher compared to FP7 (Reillon, V, 2017)

1.1 The breakdown of the EU Framework Programme for Research \& Innovation Horizon 2020 budget and societal challenges share.

Before proceeding to this study, we took in consideration Framework Program Horizon 2020 breakdown of the budget, issued at 25 June 2015 (European, U. 2015). So, Horizon 2020 budget was structured around three pillars: Excellent Science (32,38\%), Industrial Leadership (22\%) and Societal Challenges $(38,26 \%)$. Taking into account EU governance, the breakdown of the Horizon 2020 budget (25 June 2015) for Societal challenges (28.629,6 million euros) is done according with (European, $\mathrm{U}$. 2015) ANNEX II, page 31.

Net EU Contribution (EUR) to Romania by thematic priority Horizon 2020 is presented in Horizon 2020 Country Profile (Mashup) Participation in Programmes (Horizon Country Profile , 2020). Within our paper we took in consideration all Horizon 2020 components (Horizon 2020, Sections ). A lot of projects are oriented according to the European Commission's decisions regarding the role of Horizon 2020 on circularity based economies (Brussels,2.7.2014, COM , 2014). Jaana Puukka, 2018 (Puukka, J., \& Lagiou, D , 2018) considered that the mid-term evaluation of Horizon 2020 projects is very important. Regarding this, she highlighted two challenges: the concentration of financing according to the participants and their geographical representation.

Romanian Research Executive Agency UEFISCDI, 2017 (UEFISCDI, Info Day on Policy Instruments under Horizon 2020, 2017), believes that the cause for which Romania had a low participation in the framework programs is related to: insufficient national funds allocated to research and development, lack of simultaneous action of national research systems with EU research systems and low access to international research networks ". Sana (2014) considered that circularity-based economies contribute to sustainable development, assessing that the European Union could save over 630 billion euros per year through the efficient use of resources (Sana \& Stokkink ,2014).

Simona Moagăr-Poladian et al., 2017, pointed out that the countries of the eastern part of the European Union had a reduced capacity to absorb the financing for research and development and remained well below the budget funds approved by the European Commission (Moagar-Poladian\& Paunica, 2017).

According to Eugenia Gusilov., 2017, the fact that Romania is in the last position between the EU-28 in terms of innovation shows that our country has a low capacity for innovation, despite the welltrained human resources. She considers that the main reason for this inadequate situation is that, at the national level, we have few completed projects in the private sector and the "top-down" innovation approach is not efficient (Gusilov, 2017).

1.2 The performance gap in FP participation: the Romanian case

In figure 1 it is presented the structure of the Policy Support Facility Panel (PSF) proposals for 
entrepreneurs in Romania.

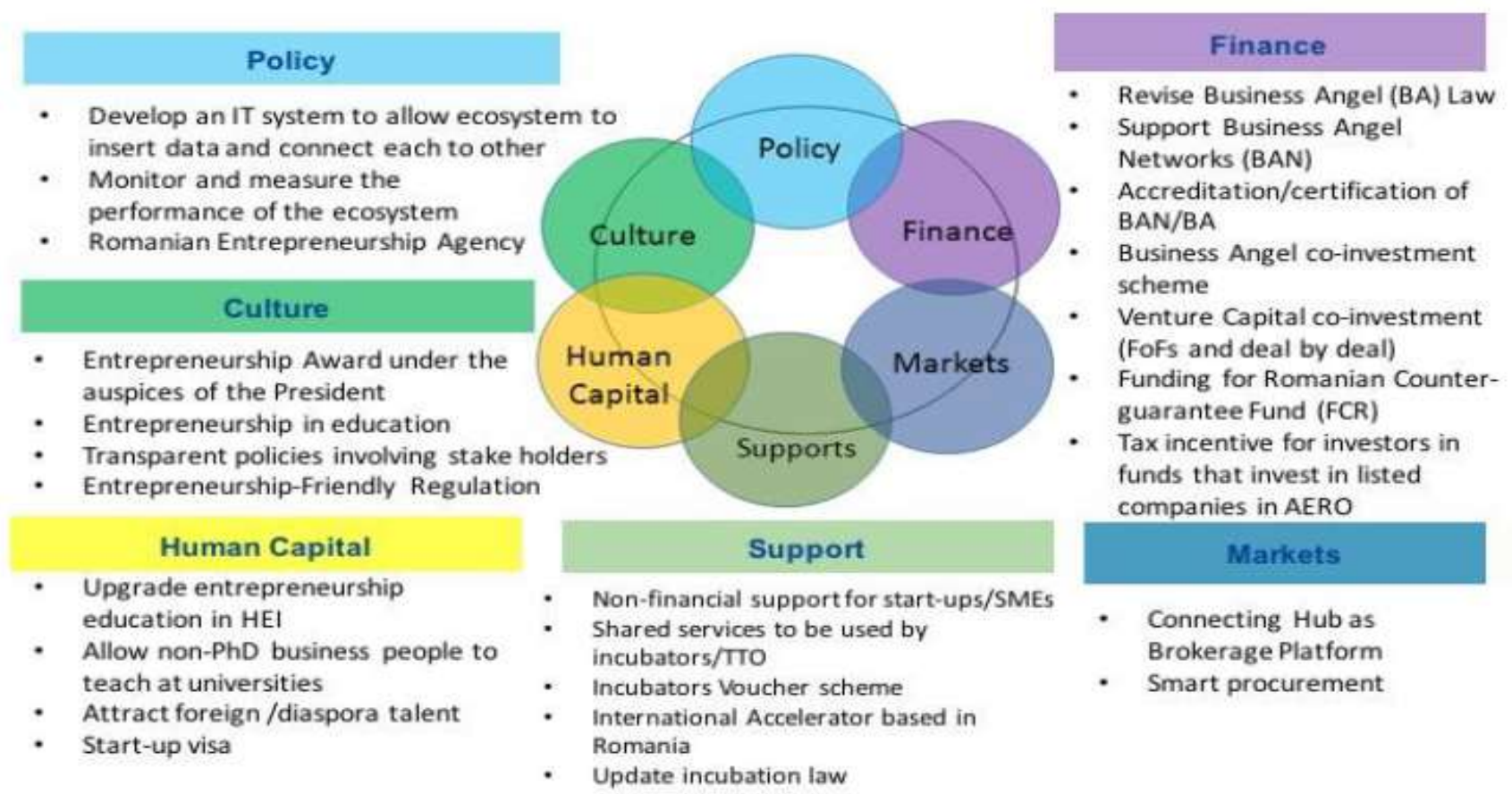

Figure 1: The structure of the (PSF) proposals for entrepreneurs in Romania. Source: PSF Panel (UEFISCDI, Specific Support to Romania, 2017) .

According with European Innovation Scoreboard 2017, the "Modest Innovators" performing group consists of only two countries: Bulgaria and Romania (European Commission.European Innovation Scoreboard, 2017). Over time, the Romanian performance decreased compared to the average of the EU countries, but after a strong decrease between 2011 and 2015, this performance started to increase after 2015 (European Commision. SBA Fact Sheet Romania ,2016). The cause of this change is that in 2014, two important strategic documents have been issued by Romanian Government. These documents were as follows: "Government Strategy for development of SMEs and business environment - Horizon 2020" and the 'Romanian National Strategy for Research, Development and Innovation 2014-2020'. (European Commision. 2016 SBA Fact Sheet Romania, 2016).

To note that the SPIRE PPP Sustainable Process Industry (SPIRE) Public-Private Partnerships PPP and JTI BBI Bio-Based Industries Joint Undertaking are supported by the Horizon 2020 Framework Program and actively contribute to the implementation of the circular economy (European Commision ,Industrial Research and Innovation ). (About BBI JU, BBI JU Stakeholder Forum 2019)

\subsection{Material and methods}

2.1 Material empirical data (European Commision,,2014)

The data on which our proposed model is developed consist of European Commission experts' elicitation from the Table 1: "The contribution of various Horizon 2020 parts to the circular economy" [9]. Based on European Commission experts' elicitation, the contribution of the various Horizon 2020 (Brussels,2.7. COM ,2014) components to all the elements of the circular economy is presented in Table 1 , below.

Within Table 1, European Commision experts have established the level of contribution of the various parts of Horizon 2020 to the circular economy using the plus sign (+) as following: 0 No contribution, + Important contribution; ++ Very important contribution. 
Table 1. The contribution of various Horizon 2020 components to the circular economy [9]

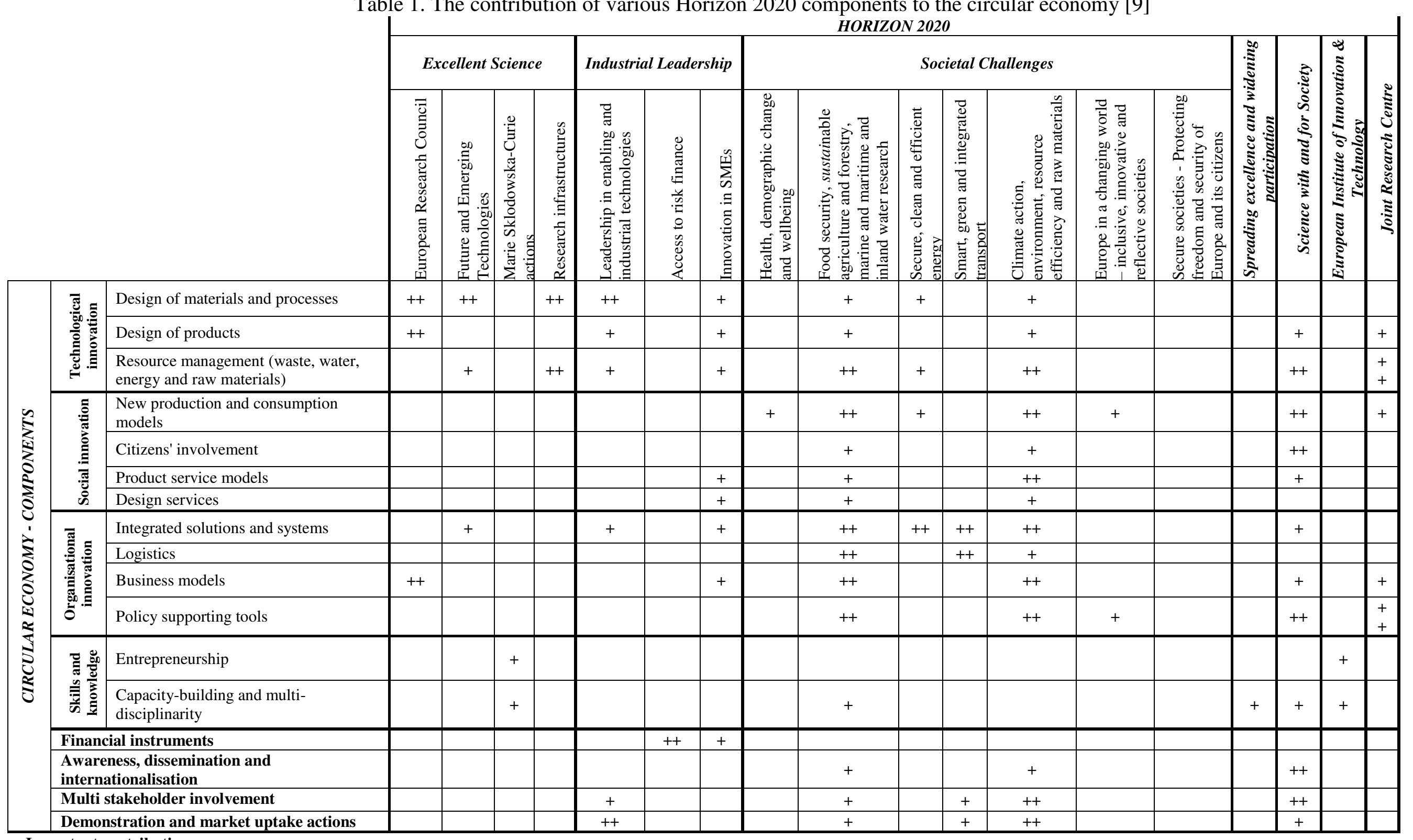

+ Important contribution

++ Very important contribution 
Governments and businesses are increasingly in their need of moving to the circular economy due to the dangerous climatic changes and the lack of material, human and financial resources. Circular Economy (EC) is described as an economic system which aims to preserve materials as long as possible. Thus, CE is based on three key principles: optimization use of resources, efficient use of products and total recovery of waste ("zero waste" concept).

In order to increasing European Union economic competitiveness and resilience, European Commission is focused on promotion and adoption of a circular model as a key critical issue for success at any economic and social level of member states.

In 2012, European Commission communication called "A Stronger European Industry for Growth and Economic Recovery" (CCOM , 2012) recommends a focus on innovations and investments, with direct reference to green manufacturing technologies, recycling according to EU standards and the move towards to circular economy. A new circular economy proposal had been officially launched in 2015 by European Commission in order to stimulate competitiveness within EU member states, increase the number of jobs and produce sustainable development (CCOM, 2015).

According with "The Communication from the commission to the European Parliament (European Commision,,2014) and Table 1, European Commission experts had identified 17 circular economy components as following:

11 directions for circular economy innovation parts, 2 directions for "Skills \& knowledge" and 4 directions for others.

\subsubsection{The linear model}

The used linear model highlights how the values of 18 criteria related to the European Commission experts' elicitation ((European Commision,,2014), (Table 1) were combined into an AcHP (Acj) overall value.

The model used shows the possibilities by which the values attributed to the 18 criteria highlighted by the European Commission experts' elicitation (European Commision,,2014) (Table 1) were combined into an AcHP (Acj) overall value.

As regards the key concepts of the circular economy, it must be properly integrated between the three basic components of the Horizon 2020 program (parts I,II an III (European Commision,,2014) .

The proposed AcHP (Acj) overall value highlights the strong integration within the all parts of Horizon 2020 program.

\subsubsection{The main objective of the current research}

In order to increase the level of EU fundings for a research project, it must obtain very good evaluations according to the criteria required by quality in Science\&Technology (Evaluation criteria in Horizon 2020; 2017) .

Using data from the document ((European Commision,,2014), it is calculated AcHP $\left(\mathrm{A}_{\mathrm{cj}}\right)$ which emphasize the strong integration across the all parts of Horizon 2020 and the effect of it on Net EU contribution by thematic priority within EU Framework Programme for Research \& Innovation Horizon 2020. Based on AcHP $\left(\mathrm{A}_{\mathrm{cj}}\right)$ values, it is calculated $\mathrm{PI}_{\mathrm{CE}}$ value.

The basic objectives of the research were:

- To calculate AcHP $\left(\mathrm{A}_{c j}\right)$ that emphasizes the strong integration across the all parts of Horizon 2020 and the effect of it on Net EU contribution by thematic priority within Horizon 2020 programs .

- To calculate Performance Index of the circular economy $\mathrm{PI}_{\mathrm{CE}}$ value, based on $\mathrm{AcHP}\left(\mathrm{A}_{c j}\right)$ values.

- To support the decision-making of EU experts and project managers, taking in consideration the European Commission's proposal for the next R\&D program called Horizon Europe (it will start in 2021) (About BBI JU, BBI JU Stakeholder Forum 2019).

So, we proposed two unique calculation models for AcHP (Acj) and PIce.

In our case, the used method considers $\mathrm{AcHP}\left(\mathrm{A}_{c j}\right)$ as a function 18 components of Horizon 2020 $\operatorname{program}\left(\mathrm{C}_{j}\right)$.

The study considered the weighted reciprocal links of criterion score $\mathrm{S}_{c j}$, contribution factor $\mathrm{X}_{i j}$, and circular economy components $\mathrm{S}_{\text {ecvi }}$, (see Equation 3 ).

In our research, we started with variables from Table 1, based on European Commission experts' elicitation. 
Thus, we considered three research hypotheses:

H1. There is a positive relationship between the Horizon 2020 program components and Circular Economy Components.

H2. AcHP (Acj) emphasizes the strong integration across the Horizon 2020 components.

H3. PI $I_{\mathrm{CE}}$ could be used as a European Commission benchmark in comparative analyzes with all EU state and non EU states.

In order to verify our research hypothesis, based on EU document (Table 1 [3]), this study has created three transformation matrices represented in tables 3,4 and 5.

\subsection{Methods}

Our research methodology uses documents classified as official EU sources.

Our research uses the Multi-Criteria Decision Analysis (MCDA) method, which applies specific criteria to evaluate different decisions (Linkov \& Moberg ,2011).

MCDA scores these decisions based on the opinion of the different experts of the European Commission (Table 1) and measurable performance data of circular economy components.

The matrix from Table 3 asseses AcHP $\left(\mathrm{A}_{c j}\right)$ correlation with real distribution of Horizon 2020 components and helps us to find the necessary activities and features that need to be improved within future Horizon Europe program (Linkov \& Moberg ,2011).

The basic criteria $\left(C_{j}, j=1, \ldots, 18\right)$ represent the contribution of Horizon 2020 components over 17 Circular Economy Components"._These criteria were highlighted in Table 1.

According to the Commission communication ((European Commision,,2014), these basic criteria $\left(C_{j}\right)$ are key principles highlighted by each component of Horizon 2020. Also, the 17 Circular Economy Components are key principles of it.

According to ISO 20400:2017 (ISO 20400, 2017), the Circular Economy uses product redesign in planning the production systems and aims to keep all material resources to the highest efficiency throughout their life cycle.

Calculation of the Circular Economy performance indicators $\mathrm{CE}_{\mathrm{pi}}$ is based on criteria $\mathrm{C}_{j}$ (score $\mathrm{Nj}$ from Table 4) and the scores of circular economy indicators after the calculation of AcHP $\mathrm{Ac}_{\mathrm{j}}$.

The new proposed method is based on the Horizon 2020 components $\left(\mathrm{C}_{j}\right)$ and Circular Economy Components $\left(\mathrm{Secv}_{\mathrm{i}}\right)$. It contains the following 7 steps:

1. Achievement of the formal model of the matrix (Table 2);

2. Organization of the data in Table 3 , where the variable of contribution factor $X_{i j}$ could be coded and take values as follows:

- 0 if Horizon 2020 components have no contribution to CE Components;

- 1 if Horizon 2020 components have an important contribution to CE Components;

- 2 if Horizon 2020 components have a very important contribution to CE Components;

3. Achievement of the direct-relation matrix (Table 4);

4. Calculation of $\mathrm{Scj}$ for each $\mathrm{C}_{j}\left(\mathrm{C}_{j}, j=1 \ldots 18\right)$;

5. Calculation of 17 secvences of the circular economy - components (Secvi);

6. Calculation of AcHP (Acj) for each of 18 basic criteria.

7. Calculation of Performance Index of the circular economy PI $\mathrm{IE}_{\mathrm{CE}}$

The algorithm for the new proposed methodology is presented in Figure 2. 


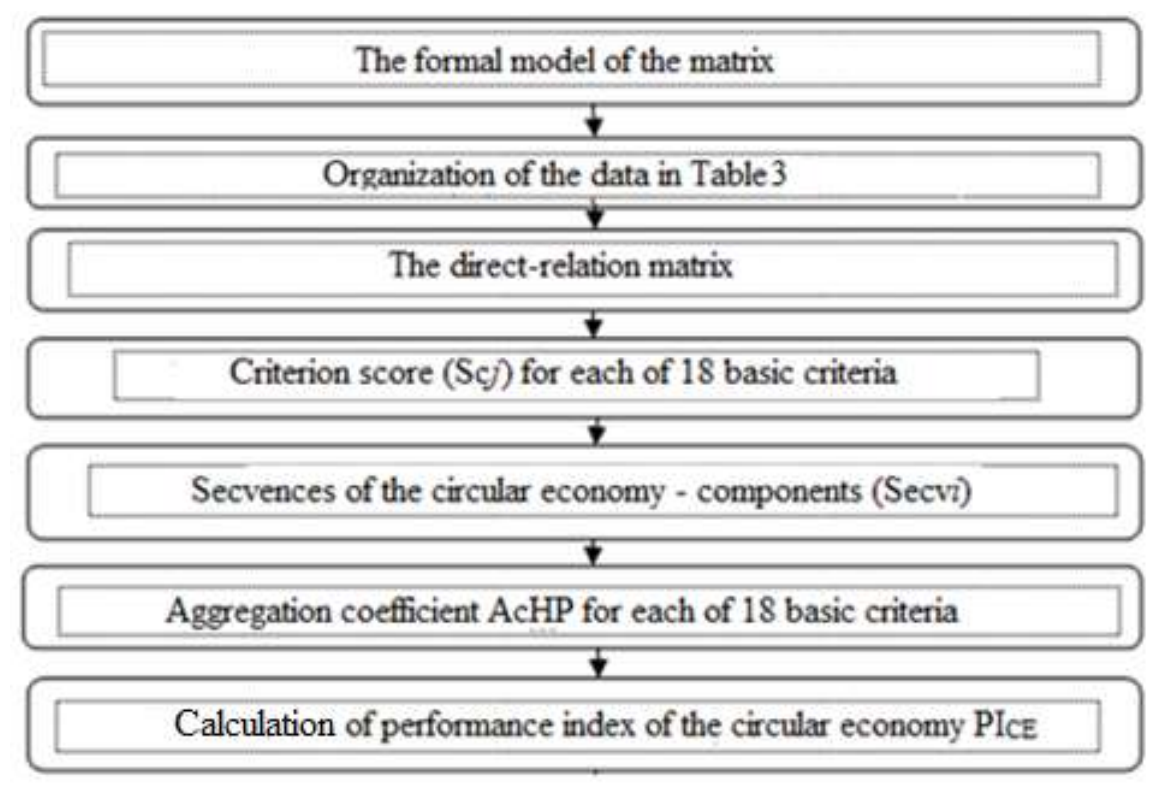

Figure 2. The algorithm for the new proposed methodology

\subsection{Theory/calculation section}

\subsection{Theory section}

The Matrix formal model is shown in Table 2.

Table 2. The Matrix formal model

\begin{tabular}{|c|c|c|c|c|}
\hline & \multicolumn{4}{|c|}{$\begin{array}{c}\text { Horizon } 2020 \text { contribution to the circular economy according with } \\
\text { Horizon } 2020 \text { components ( } 18 \text { basic criteria) }\end{array}$} \\
\hline $\begin{array}{l}\text { Circular Economy } \\
\text { Components }\end{array}$ & $\mathrm{C}_{1}$ & $\mathrm{C}_{2}$ & $\mathrm{C}_{i}$ & $\mathrm{C}_{18}$ \\
\hline $\operatorname{Sec}_{1}$ & $\mathrm{x}_{11}$ & $\mathrm{X}_{12}$ & $\ldots \ldots$ & $\mathrm{x}_{1 \mathrm{j}}$ \\
\hline $\mathrm{Secv}_{2}$ & $\mathrm{X}_{21}$ & $\mathrm{X}_{22}$ & $\ldots .$. & $\mathrm{x}_{2 \mathrm{j}}$ \\
\hline$\ldots \ldots$. & $\ldots .$. & $\ldots \ldots$ & $\ldots \ldots$ & $\ldots \ldots$ \\
\hline $\mathrm{Secv}_{\mathrm{i}}$ & $\mathrm{X}_{\mathrm{i} 1}$ & $\mathrm{X}_{\mathrm{i} 2}$ & $\ldots .$. & $\mathrm{x}_{\mathrm{ij}}$ \\
\hline ........ & $\ldots .$. & ....... & $\ldots \ldots$ & $\ldots \ldots$ \\
\hline Secvi7 $_{17}$ & $\mathrm{X}_{\mathrm{n} 1}$ & $\mathrm{X}_{\mathrm{n} 2}$ & $\ldots .$. & $\mathrm{X}_{\mathrm{nj}}$ \\
\hline AcHP & $\mathrm{AcHP}_{1}$ & $\mathrm{AcHP}_{2}$ & $\ldots .$. & $\mathrm{AcHP}_{18}$ \\
\hline
\end{tabular}

For each of the 18 Horizon 2020 components, it is calculated $\mathrm{S}_{c j}$, as following:

$$
\mathrm{Sc}_{\mathrm{j}}=\sum_{i=1}^{17} \mathrm{Xij} \quad(\mathrm{j}=1 . .18)
$$

Where:

$\mathrm{n}$ - The number of Circular Economy Components

$\mathrm{X}_{\mathrm{ij}}$ - The contribution factor of Horizon 2020 components:

3.1.1 The contribution factor values

According its contribution over Circular Economy Components, the contribution factor $\mathrm{X}_{i j}$ could have three values $(0,1$ and 2 ; see the step 2 of the algorithm for the new proposed methodology).

If all the criteria $\mathrm{C}_{j}$ represent the contribution Circular Economy Components, then $\mathrm{S}_{c j}$ has the highest value of 34. The calculation of Horizon 2020 components contribution to the Circular Economy starts from the matrix formal model (Table 2).

In the formal matrix model, our data has been entered according to the following rules:

1. Based on the EU document [9] and Table 1, all the components of Framework Program Horizon 2020 (Cj) have been identified and set. These were used as basic criteria for calculating their contribution to the circular economy components".

2. According to $\mathrm{Cj}$ values, for the calculation of $\mathrm{AcHP}$, the scores were established for all the 17 components of the circular economy.

3. Based on European Commision experts level of contribution signs $(0,+$ and ++$)$, it is developed and analyzed the matrix from table 3 
Table 3. The Matrix with contribution of various Horizon 2020 components to the circular economy components

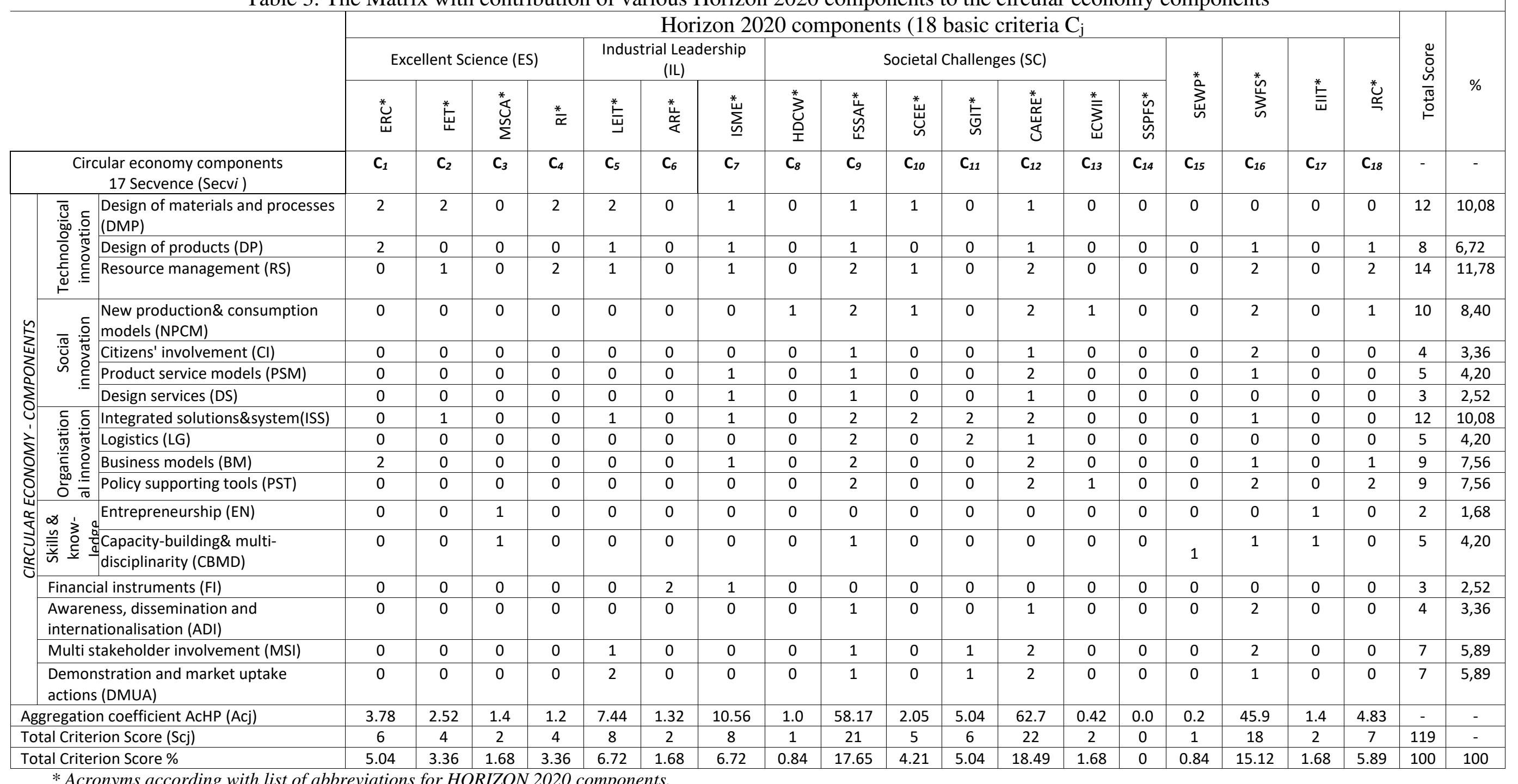

\begin{tabular}{l|l|l|l|l|l|l|}
$*$ * Acronyms according with list of abbreviations for HORIZON 2020 components.
\end{tabular}

Considering this data from the Table 3, we observe the existence of a positive relationship between the Horizon 2020 components' and Circular Economy

Components' and, therefore, the Hypothesis H1 is validated. 


\subsection{The calculation section}

\subsubsection{The calculation of ( $\mathrm{Scj})$}

For every Horizon 2020 component, it is calculated $S_{\mathrm{cj}}$ as following (1) :

$$
\mathrm{Sc}_{\mathrm{j}}=\sum_{i=1}^{17} \mathrm{Xij} \quad(\mathrm{j}=1 . .18)
$$

According to table 4, the following results:

$$
\mathrm{Sc}_{1}=\sum_{i=1}^{17} \mathrm{Xi} \begin{aligned}
& =\left(\mathrm{X}_{11}+\mathrm{X}_{21}+\mathrm{X}_{31}+\mathrm{X}_{41}+\mathrm{X}_{51}+\mathrm{X}_{61}+\mathrm{X}_{71}+\mathrm{X}_{81}+\mathrm{X}_{91}+\mathrm{X}_{101}+\mathrm{X}_{111}+\right. \\
& \\
& \left.\mathrm{X}_{121}+\mathrm{X}_{131}+\mathrm{X}_{141}+\mathrm{X}_{151}+\mathrm{X}_{161}+\mathrm{X}_{171}\right)= \\
& (2+2+0+0+0+0+0+0+0+2+0+0+0+0+0+0+0)=6
\end{aligned}
$$

Following the same calculation method of Scj, we obtained the following results:

$\mathrm{Sc}_{2}=4 ; \mathrm{Sc}_{3}=2 ; \mathrm{Sc}_{4}=4 ; \mathrm{Sc}_{5}=8 ; \mathrm{Sc}_{6}=2 ; \mathrm{Sc}_{7}=8 ; \mathrm{Sc}_{8}=1 ; \mathrm{Sc}_{9}=21 ; \mathrm{Sc}_{10}=5 ; \mathrm{Sc}_{11}=6 ;$

$\mathrm{Sc}_{12}=22 ; \mathrm{Sc}_{13}=2 ; \mathrm{Sc}_{14}=0 ; \mathrm{Sc}_{15}=1 ; \mathrm{Sc}_{16}=18 ; \mathrm{Sc}_{17}=2 ; \mathrm{Sc}_{18}=7$;

3.2.2 Calculation of 17 secvences (components) of the circular economy

For each of the 17 secvences (components) of the circular economy, Secvi is determined with the relation (2):

$$
\text { Secvi }=\sum_{j=1}^{18} X i j \quad(\mathrm{i}=1 . .17)
$$

Thus, it follows Secvi calculation:

$\operatorname{Secv}_{1}=(1+2+2+0+2+2+0+1+0+1+1+0+1+0+0+0+0+0+0)=12$

Following the same calculation method of Secvi, we obtained the following results:

$\operatorname{Secv}_{2}=8 ; \operatorname{Secv}_{3}=14 ; \mathrm{Secv}_{4}=10 ; \mathrm{Secv}_{5}=4 ; \mathrm{Secv}_{6}=5 ; \mathrm{Secv}_{7}=3 ; \operatorname{Secv}_{8}=12 ; \mathrm{Secv}_{9}=5 ; \mathrm{Secv}_{10}=9 ;$

$\operatorname{Secv}_{11}=9 ; \operatorname{Secv}_{12}=2 ; \operatorname{Secv}_{13}=5 ; \operatorname{Secv}_{14}=3 ; \operatorname{Secv}_{15}=4 ; \operatorname{Secv}_{16}=7 ; \operatorname{Secv}_{17}=7$;

3.2.3 The calculation of AcHP $\left(\mathrm{A}_{c j}\right)$

The coefficient AcHP represents the complex contribution of 18 Horizon 2020 components (the basic criteria from Table 3) on 17 Circular economy components.

The coefficient $\operatorname{AcHP}\left(\mathrm{A}_{c j}\right)$ was calculated using the relation (3):

$$
\text { Acj }=\operatorname{Scj} \sum_{\mathrm{I}=1}^{17} \frac{\mathrm{XIJ}}{\mathrm{SECVI}} \quad(\mathrm{j}=1 . .18)
$$

Thus, it follows AcHP calculation:

$\mathrm{ACHP} 1=6\left(\frac{2}{12}+\frac{2}{8}+\frac{0}{14}+\frac{0}{10}+\frac{0}{4}+\frac{0}{5}+\frac{0}{3}+\frac{0}{12}+\frac{0}{5}+\frac{2}{9}+\frac{0}{9}+\frac{0}{2}+\frac{0}{5}+\frac{0}{3}+\frac{0}{4}+\frac{0}{7}+\frac{0}{7}\right)=$ $=6(0,16+0,25+0+0+0+0+0+0+0+0,22+0+0+0+0+0+0+0)=6(0.63)=3.78$

Following the same calculation method of Acj, we obtained the following results:

ACHP2 $=2,52 ;$ ACHP3 $=1.40 ;$ ACHP $4=1.20 ;$ ACHP5 $=7.44 ;$ ACHP6 $=1.32 ;$ ACHP7 $=10.56 ;$

$\mathrm{ACHP}=1.00 ; \mathrm{ACHP} 9=58.17 ; \mathrm{ACHP} 10=2.05 ;$ ACHP11 $=5.04 ;$ ACHP12 $=62.7 ;$ ACHP13 $=0.42$;

ACHP14 $=0.00 ;$ ACHP15 $=0.20 ;$ ACHP16 $=45.9 ;$ ACHP17 $=1.40 ;$ ACHP18 $=4.83$;

3.2.4 The calculation of Performance Index of the Circular Economy PI $\mathrm{CE}$

Starting from the fact that $\mathrm{AcHP}\left(\mathrm{Ac}_{\mathrm{j}}\right)$ represents the complex contribution of 18 Framework

Program Horizon 2020 components on Circular economy components we proposed a model to find Circular Economy performance indicators $\left(\mathrm{CE}_{\mathrm{pi}}\right)$ and to calculate $\mathrm{PI} \mathrm{I}_{\mathrm{CE}}$ as the sum of every $C E_{p i .}$

After performing the calculations and representing the values of $\mathrm{A}_{c j}$, we can conclude that AcHP $\left(A_{c j}\right)$ emphasizes the strong integration across the all parts of Horizon 2020 and the effect of its on Net EU contribution (EUR) by thematic priority within Horizon 2020. So, we consider that Hypotesis $\mathrm{H} 2$ is validated. According with AcHP criteria $\left(A_{c j}, j=1, \ldots, 18\right)$ and the assessment of European Commission experts, the value of scores were established for Circular Economy components (17 key principles): DMP, DP, RS, NPCM, CI, PSM, DS, ISS, LG, BM, PST, EN, CBMD, FI, ADI, MSI, DMUA (see Table 4). 
Table 4. Criteria $\mathrm{C}_{\mathrm{j}}$ for Horizon 2020 components and the scores assigned for every $17^{\text {th }}$ Circular Economy key principles $\left(\mathrm{N}_{j}\right)$



* The acronyms are set according with list of abbreviations for Horizon 2020 components. 
“TOTAL SUM OF SCORES” for each of $\mathbf{N}_{j}$ criteria was determined by the next 17 relations:

$$
\begin{aligned}
& \mathrm{S}_{\mathrm{DMP}}=\sum_{j=1}^{18} N_{j} \mathrm{DMP}=12 \\
& (\mathrm{j}=1 . .18) \\
& \mathrm{SDP}=\sum_{j=1}^{18} N_{j} \mathrm{DP}=8 \\
& \mathrm{~S}_{\mathrm{RS}}=\sum_{j=1}^{18} N_{j} \mathrm{RS}=14 \\
& (\mathrm{j}=1 . .18) \\
& (\mathrm{j}=1 . .18) \\
& \mathrm{S}_{\mathrm{NPCM}}=\sum_{j=1}^{18} N_{j} \mathrm{NPCM}=10 \\
& (\mathrm{j}=1 . .18) \\
& \mathrm{S}_{\mathrm{CI}}=\sum_{j=1}^{18} N_{j} \mathrm{CI}=4 \\
& \mathrm{SPSM}=\sum_{j=1}^{18} N_{j} \mathrm{PSM}=5 \\
& \mathrm{SDS}=\sum_{j=1}^{18} N_{j} \mathrm{DS}=3 \\
& \text { SISS }=\sum_{j=1}^{18} N_{j} \text { ISS }=12 \\
& \mathrm{~S}_{\mathrm{LG}}=\sum_{j=1}^{18} N_{j} \mathrm{LG}=5 \\
& \mathrm{~S}_{\mathrm{BM}}=\sum_{j=1}^{18} N_{j} \mathrm{BM}=9 \\
& \mathrm{SPST}=\sum_{j=1}^{18} N_{j} \mathrm{PST}=9 \\
& \mathrm{~S}_{\mathrm{EN}}=\sum_{j=1}^{18} N_{j} \mathrm{EN}=2 \\
& \mathrm{~S}_{\text {свмD }}=\sum_{j=1}^{18} N_{j} \mathrm{CBMD}=5 \\
& \mathrm{~S}_{\mathrm{FI}}=\sum_{j=1}^{18} N_{j} \mathrm{FI}=3 \\
& \mathrm{~S}_{\mathrm{ADI}}=\sum_{j=1}^{18} N_{j} \mathrm{ADI}=4 \\
& \mathrm{~S}_{\mathrm{MSI}}=\sum_{j=1}^{18} N_{j} \mathrm{MSI}=7 \\
& \mathrm{~S}_{\mathrm{DMUA}}=\sum_{j=1}^{18} N_{j} \mathrm{DMUA}=7
\end{aligned}
$$

The calculation of the circular economy performance indicators $\mathrm{CE}_{\mathrm{pi}}$ is done according with value of $\mathrm{C}_{j}$ (score $\mathrm{Nj}$ from Table 4 ) and the scores assigned to the circular economy indicators after the calculation of $\mathrm{Ac}_{\mathrm{j}}$. This calculation is shown in the Table 5, below. The calculation of $\mathrm{CE}_{\mathrm{pi}}$ (Circular Economy performance indicator) is made for each of $\mathrm{N}_{j}$ criteria according with equation (21) as follows:

$$
\mathrm{CE}_{\mathrm{pi}}=\sum_{j=1}^{18} N_{j} \text { Acj } \quad(\mathrm{j}=1 . .18)
$$


Table 5. Calculation of the circular economy performance indicators $\mathrm{CE}_{\mathrm{pi}}$

\begin{tabular}{|c|c|c|c|c|c|c|c|c|c|c|c|c|c|c|c|c|c|c|}
\hline \multirow{4}{*}{$\mathrm{C}_{\mathrm{j}}$} & \multirow{4}{*}{$\mathrm{A}_{\mathrm{cj}}$} & \multicolumn{17}{|c|}{ The $17^{\text {th }}$ Circular Economy key principles and their performance indicators } \\
\hline & & DMP & DP & RS & NPCM & $\mathrm{CI}$ & PSM & DS & ISS & LG & BM & PST & EN & CBMD & FI & ADI & MSI & DMUA \\
\hline & & $\mathrm{Nj}_{\mathrm{DMP}} \cdot$ & $\mathrm{Nj}_{\mathrm{DP}}$ & $\mathrm{Nj}_{\mathrm{RS}}$ & $\mathrm{Nj}_{\mathrm{NPCM}} \cdot \mathrm{A}$ & $\mathrm{Nj}_{\mathrm{Cl}}$ & $\mathrm{Nj}_{\mathrm{PSM}} \cdot$ & $\mathrm{Nj}_{\mathrm{DS}}$ & $\mathrm{Nj}_{\mathrm{ISS}}$ & $\mathrm{Nj}_{\mathrm{LG}}$ & $\mathrm{Nj}_{\mathrm{BM}}$ & $\mathrm{Nj}_{\mathrm{PST}} \cdot \mathrm{A}_{c j}$ & $\mathrm{Nj}_{\mathrm{EN}}$ & $\mathrm{Nj}_{\text {СвMD }}$ & $\mathrm{Nj}_{\mathrm{FI}}$ & $\mathrm{Nj}_{\mathrm{ADI}} \cdot \mathrm{A}_{c j}$ & $\mathrm{Nj}_{\mathrm{MSI}}$ & $\mathrm{Nj}_{\mathrm{DMUA}}$ \\
\hline & & $\mathrm{A}_{c j}$ & $\mathbf{A}_{c j}$ & $\mathrm{~A}_{c j}$ & $c^{c}$ & $\mathrm{~A}_{c j}$ & $\mathrm{~A}_{c j}$ & $\mathbf{A}_{c j}$ & $\mathrm{~A}_{c j}$ & $\mathrm{~A}_{c j}$ & $\mathrm{~A}_{c j}$ & & $\mathrm{~A}_{c j}$ & $\mathrm{~A}_{c j}$ & $\mathrm{~A}_{c j}$ & & $\mathrm{~A}_{c j}$ & $\mathrm{~A}_{c j}$ \\
\hline ERC & 3,78 & 7,56 & 7,56 & 0 & 0 & 0 & 0 & 0 & 0 & 0 & 7,56 & 0 & 0 & 0 & 0 & 0 & 0 & 0 \\
\hline FET & 2,52 & 5,04 & 0 & 2,52 & 0 & 0 & 0 & 0 & 2,52 & 0 & 0 & 0 & 0 & 0 & 0 & 0 & 0 & 0 \\
\hline MSCA & 1,4 & 0 & 0 & 0 & 0 & 0 & 0 & 0 & 0 & 0 & 0 & 0 & 1,4 & 1,4 & 0 & 0 & 0 & 0 \\
\hline RI & 1,2 & 2,4 & 0 & 2,4 & 0 & 0 & 0 & 0 & 0 & 0 & 0 & 0 & 0 & 0 & 0 & 0 & 0 & 0 \\
\hline LEIT & 7,44 & 14,88 & 7,44 & 7,44 & 0 & 0 & 0 & 0 & 7,44 & 0 & 0 & 0 & 0 & 0 & 0 & 0 & 7,44 & 14,88 \\
\hline ARF & 1,32 & 0 & 0 & 0 & 0 & 0 & 0 & 0 & 0 & 0 & 0 & 0 & 0 & 0 & 2,64 & 0 & 0 & 0 \\
\hline ISME & 10,56 & 10,56 & 10,56 & 10,56 & 0 & 0 & 10,56 & 10,56 & 10,56 & 0 & 10,56 & 0 & 0 & 0 & 10,56 & 0 & 0 & 0 \\
\hline HDCW & 1,0 & 0 & 0 & 0 & 1,0 & 0 & 0 & 0 & 0 & 0 & 0 & 0 & 0 & 0 & 0 & 0 & 0 & 0 \\
\hline FSSAF & 58,17 & 58,17 & 58,17 & 116,34 & 116,34 & 58,17 & 58,17 & 58,17 & 116,34 & 116,34 & 116,34 & 116,34 & 0 & 58,17 & 0 & 58,17 & 58,17 & 58,17 \\
\hline SCEE & 2,05 & 2,05 & 0 & 2,05 & 2,05 & 0 & 0 & 0 & 4,1 & 0 & 0 & 0 & 0 & 0 & 0 & 0 & 0 & 0 \\
\hline SGIT & 5,04 & 0 & 0 & 0 & 0 & 0 & 0 & 0 & 10,08 & 10,08 & 0 & 0 & 0 & 0 & 0 & 0 & 5,04 & 5,04 \\
\hline CAERE & 62,7 & 62,7 & 62,7 & 125,4 & 125,4 & 62,7 & 125,4 & 62,7 & 125,4 & 62,7 & 125,4 & 125,4 & 0 & 0 & 0 & 62,7 & 125,4 & 125,4 \\
\hline ECWII & 0,42 & 0 & 0 & 0 & 0,42 & 0 & 0 & 0 & 0 & 0 & 0 & 0,42 & 0 & 0 & 0 & 0 & 0 & 0 \\
\hline SSPFS & 0 & 0 & 0 & 0 & 0 & 0 & 0 & 0 & 0 & 0 & 0 & 0 & 0 & 0 & 0 & 0 & 0 & 0 \\
\hline SEWP & 0,2 & 0 & 0 & 0 & 0 & 0 & 0 & 0 & 0 & 0 & 0 & 0 & 0 & 0,2 & 0 & 0 & 0 & 0 \\
\hline SWFS & 45,9 & 0 & 45,9 & 91,8 & 91,8 & 91,8 & 45,9 & 0 & 45,9 & 0 & 45,9 & 91,8 & 0 & 45,9 & 0 & 91,8 & 91,8 & 45,9 \\
\hline EIIT & 1,4 & 0 & 0 & 0 & 0 & 0 & 0 & 0 & 0 & 0 & 0 & 0 & 1,4 & 1,4 & 0 & 0 & 0 & 0 \\
\hline $\mathrm{JRC}$ & 4,83 & 0 & 4,83 & 9,66 & 4,83 & 0 & 0 & 0 & 0 & 0 & 4,83 & 9,66 & 0 & 0 & 0 & 0 & 0 & 0 \\
\hline & & $\begin{array}{c}\text { CEpiDMP } \\
=\end{array}$ & CEpiDP & CEpiRS & $\begin{array}{c}\text { CEpiNPC } \\
M\end{array}$ & CEpiCI & CEpiPSM & $\begin{array}{c}\text { CEpiDS } \\
=\end{array}$ & $\begin{array}{c}\text { CEpiISS } \\
=\end{array}$ & CEpiLG & CEpiBM & CEpiPST & CEpiEN & $\begin{array}{c}\text { CEpiCBM } \\
\text { D }\end{array}$ & CEpiFI & CEpiADI & CEpiMSI & $\begin{array}{c}\text { CEpiDMU } \\
\text { A }\end{array}$ \\
\hline CEpiNj & - & $\begin{array}{c}= \\
163,36\end{array}$ & $\begin{array}{c}= \\
197,16\end{array}$ & $\begin{array}{c}= \\
368,17\end{array}$ & $\begin{array}{c}\text { M } \\
= \\
341,84\end{array}$ & $\begin{array}{c}= \\
212,67\end{array}$ & $\begin{array}{c}= \\
240,56\end{array}$ & $\begin{array}{c}= \\
131,43\end{array}$ & $\begin{array}{c}= \\
322,34\end{array}$ & $\begin{array}{c}= \\
189,12\end{array}$ & $\begin{array}{c}= \\
310,59\end{array}$ & $\begin{array}{c}= \\
343,62\end{array}$ & $\begin{array}{c}= \\
2,8\end{array}$ & $\begin{array}{c}\text { D } \\
= \\
107,07\end{array}$ & $\begin{array}{c}= \\
13.2\end{array}$ & $\begin{array}{c}= \\
212,67\end{array}$ & $\begin{array}{c}= \\
288,38\end{array}$ & $\begin{array}{c}\mathrm{A} \\
= \\
195,39\end{array}$ \\
\hline
\end{tabular}


In Table 5, we used the following notations:

- $\mathrm{C}_{\mathrm{j}}$ is Framework Program Horizon 2020 components' criteria;

- $A c_{j}$ is Aggregation coefficient AcHP criteria (Table 5);

- $\mathrm{CE}_{\mathrm{piNj}}$ is Circular Economy performance indicator for every $\mathrm{Nj}$ score.

PICE is the sum of every $\mathrm{CE}_{\mathrm{piNj}}$ according with the equation (22).

$$
\text { PICE }=\sum_{j=1}^{18} \operatorname{CEpi}_{j} \quad(\mathrm{j}=1 . .18)
$$

Thus, it follows the next $\mathrm{PI}_{\mathrm{CE}}$ calculation:

CEpiDMP + CepiDP + CepiRS + CEpiNPCM+ CepiCI+ CEpiPSM+CepiDS + CEpiISS + CepiLG+ CepiBM+ CEpiPST+ CepiEN+ CEpiCBMD+ CepiFI+ CEpiADI+ CEpiMSI+ CEpiDMUA = $163,36+197,16+368,17+341,84+212,67+240,56+131,43+322,34+189,12+310,59+343,62+2,8+$ $107,07+13,2+212,67+288,38+195,39=\mathbf{3 6 4 0 , 3 7}$

In this study, the value of every circular economy performance indicators $\mathrm{CE}_{\mathrm{pi}}$ is calculated in Table 5 and suggests that there is a significant correlation between $\mathrm{CE}_{\mathrm{pi}}$ and Horizon 2020 components. PICE value $(\mathbf{3 6 4 0 , 3 7 )}$ is calculated according with the important coefficients assigned by the European Commission experts in Horizon 2020 components (Table 1) (European Commision,,2014).

\subsection{Results}

In our opinion, this index $\mathrm{PI}_{\mathrm{CE}}$ (as a sum of every $\mathrm{CE}_{\mathrm{pi}}$ ) is a common valid number for all the states of the European Union that participated in the Horizon 2020 projects by 2022.

Our proposal is that $\mathrm{PI}_{\mathrm{CE}}$ can be used as a standard of the European Commission when considering the quantitative and qualitative assessment of the efficiency of Member States' access to European funds in Horizon 2020. Also, including within the future European Commission program "Horizon Europe", PI $\mathrm{CE}_{\mathrm{CE}}$ could be used as a benchmark in a comparative analysis with any of the European Union state (Hypothesis H3 is validated). For this purpose, the experts of the analyzed (compared) state must complete the Table 1(European Commision,,2014)

\subsection{Discussions}

Using $\mathrm{PI}_{\mathrm{CE}}$ we can prove that there is bidirectional causality between Framework program Horizon 2020 components and circular economy components. After the Table 1 has been completed by the most recognized national experts in European projects and circular economy, we can move to the following level: compliance with the algorithm that is presented in Figure 2.

Let think that the State $X$ from European Union has calculated state index having the PI $\mathrm{IEx}_{\mathrm{Cx}}$ notation. Compared to the PI $\mathrm{I}_{\mathrm{CE}}$ index, the $\mathrm{PI}_{\mathrm{Cex}}$ index will be analysed in the following 3 situations:

- S1: $\mathrm{PI}_{\mathrm{CE}}>\mathrm{PI}_{\mathrm{CEx}}$

- S2: $\mathrm{PI}_{\mathrm{CE}}=\mathrm{PI}_{\mathrm{Cex}}$

- S3: $\mathrm{PI}_{\mathrm{CE}}<\mathrm{PI}_{\mathrm{Cex}}$

Following the analysis, it could be concluded that the state X was performant (S3) or not (S1) in terms of its $\mathrm{PI}_{\mathrm{CE}}$ value. It is also possible to analyze the connection between the Circular Economy Components (Secvi) and the Horizon 2020 components in which the entities of the respective state took part. Taking into account the results of PI $\mathrm{IE}_{\mathrm{CE}}$ analysis of respective country, we can take into account the lessons to be learned and the measures required for project managers of future EU projects.

\subsection{Conclusions}

The unit of the research analysis is Table 1 (European Commision,,2014) In our opinion, this PICE (as a sum of every $\mathrm{CE}_{\mathrm{pi}}$ ) is a common valid number for all the states of the European Union that participated in the Horizon 2020 projects by 2022. The novelty of this study lies in our proposal that PICE could be used as a standard of the European Commission when it is considering the efficiency of Member States' access to European funds within Framework Programe Horizon 2020 and future European Unions programs. We aim to develop a unique calculation model to support European Commission future 
projects and providing new ideas for clustering their concepts. Furthermore, our main interest is to informing society, including policy makers and decision-makers, on matters relating to socio-economic aspects of European Union policy in the field of Research\&Innovation Framework Programs.

When a non - EU country enter the Horizon 2020, it respects the European Union rules described in this paper. As a consequence Circular Economy Performance Indicator (PI $\mathrm{CE}$ ) could be used as a standard for non EU countries from across the worlds which participate in EU Programmes that are using a sustainable funding policy. Regarding funding policy, K. Winans et al (Winans \& Deng ,2017) are considered that European Union states' funding initiatives on the circular economy require integrated bottom-up approaches for successful implementation and evaluation at any country level. The authors conclude that economic and regulatory instruments work properly when the governments have clear goals for all the political processes involved in their funding activities.

\section{Declarations}

Professor Vasile N. POPA has no known competing financial interests or personal relationships that could have appeared to influence the work reported in the paper:

"EU Framework Programme for Research \& Innovation contribution to the Circular Economy components",

Lecturer PhD Luminita I. POPA has no known competing financial interests or personal relationships that could have appeared to influence the work reported in the paper:

"EU Framework Programme for Research \& Innovation contribution to the Circular Economy components",

Postdoctoral student PhD Anca N. IUGA (BUTNARIU) has no known competing financial interests or personal relationships that could have appeared to influence the work reported in the paper: "EU

Framework Programme for Research \& Innovation contribution to the Circular Economy components ",

Ethics approval and consent to participate

Not applicable

\section{Consent for publication}

Not applicable

Availability of data and material

All data generated or analysed during this study are included in this published article and its supplementary information files.

\section{Competing interests}

The authors declare that they have no competing interests

\section{Funding}

The postdoctoral researcher Anca N. IUGA (BUTNARIU) was beneficiary of the Transilvania University of Brașov funding for advanced research postdoctoral internships through the project CNFIS-FDI-20190324 of the National Council for the Financing of Higher Education (15 May 2019 -15 May 2020).

\section{Authors' contributions}

VP had made substantial contributions to the acquisition, analysis and interpretation of data;

LP had made substantial contributions to the conception and design of the work;

AI(B) had made substantial contributions to calculation section, had a major contributor in writing the manuscript, had drafted the work and substantively revised it.

All authors read and approved the final manuscript (and any substantially modified version that involves the author's contribution to the study);

All authors had agreed both to be personally accountable for the author's own contributions and to ensure that questions related to the accuracy or integrity of any part of the work, even ones in which the author was not personally involved, are appropriately investigated, resolved, and the resolution documented in the literature.

\section{Acknowledgements}

The postdoctoral researcher Anca N. IUGA (BUTNARIU) was beneficiary of the Transilvania University of Braşov funding for advanced research postdoctoral internships through the project CNFIS-FDI-20190324 of the National Council for the Financing of Higher Education (15 May 2019 -15 May 2020).

We like to thank all partners for their continued efforts in making this project a success story. 


\section{Authors' information}

${ }^{1}$ Regional Department for Defense Resources Management Studies, Mihai Viteazul 130, Braşov, 500183, Romania

2 Transilvania University of Brasov, Faculty of Electrical Engineering and Computer Science, Department of Automation and Information Technologies, str. Politehnicii nr. 1, Brasov, 500024, Romania

${ }^{3}$ Transilvania University of Brasov, Postdoctoral studies, B-dul Eroilor nr. 29, Brasov, 500036, Romania *Corresponding author, email: anca.iuga@unitbv.ro ; Tel: +40 268413000 ext. 237,131. Fax: +40 268 510052

\section{List of references}

About BBI JU, BBI JU Stakeholder Forum (2019), 4 December 2019, Brussels Retrieved from http://www.bbi-europe.eu/about/about-bbi

Brunet, M., \& Aubry, M. (2016). The three dimensions of a governance framework for major public projects. International Journal of Project Management, 34, 1596-1607.

European Commision. (2014). Brussels,2.7.2014, COM(2014) 398 final (Communication from the Commission to the European Parliament, the Council, the European Economic and Social Committee and the Committee of the Regions)

http://eur-lex.europa.eu/legal-content/EN/TXT/DOC/?uri=CELEX:52014DC0398\&from=EN

Europea, U. (2015). Regulation (EU) 2015/1017 of the European Parliament and of the Council of 25 June 2015 on the European Fund for Strategic Investments, the European Investment Advisory Hub and the European Investment Project Portal and amending Regulations (EU) No 1291/2013 and (EU) No 1316/2013 - the European Fund for Strategic Investments. Official Journal of the European Union, L, 169, 58. Retrieved from https://eur-lex.europa.eu/legalcontent/EN/TXT/PDF/?uri=CELEX:32015R1017\&from=EN

European Commision. 2016 SBA Fact Sheet Romania (2016)

Retrieved from http://ec.europa.eu/DocsRoom/documents/22382/attachments/29/translations/

European Commission. European Innovation Scoreboard 2017 Methodology Report.

Retrieved from

https://en.eustat.eus/elementos/ele0014400/Methodology_Report_EIS_2017/inf0014422_i.pdf

Evaluation criteria in Horizon 2020; (2017)

https://ec.europa.eu/research/participants/data/ref/h2020/call_ptef/ef/2016-2017/h2020-call-ef-ria-ia-csa2016-17_en.pdf

Flyvbjerg, B. (2014). What you Should Know about Megaprojects and Why: An Overview. Project Management Journal, 45(2), 6-19. https://doi.org/10.1002/pmj.21409

Gusilov,E., (2017). Energy Research, Development and Innovation in Romania. Country Paper: Energy Research, Development and Innovation in Romania. Retrieved from https://www.roec.biz/project/energy-research-development-innovation-romania/

Horizon Sections. (2020) https://ec.europa.eu/programmes/horizon2020/en/h2020-sections 
Horizon. Country Profile (Mashup) Participation in Programmes; Net EU Contribution (EUR) by thematic priority (2020)

https://webgate.ec.europa.eu/dashboard/sense/app/a976d168-2023-41d8-acec-

e77640154726/sheet/0c8af38b-b73c-4da2-ba41-73ea34ab7ac4/state/0

European Commission ,Industrial research and innovation. Why the EU supports industrial research and innovation,

https://ec.europa.eu/info/research-and-innovation/research-area/industrial-research-and-innovation_en

ISO 20400:2017 Sustainable procurement - Guidance. Circular economy 3.1

https://www.iso.org/obp/ui/\#iso:std:iso:20400:ed-1:v1:en

Klakegg, O.., Williams, T., \& Magnussen, O. M. (2009, August). Governance frameworks for public project development and estimation. Project Management Institute.

Linkov, I., \& Moberg, E. (2011). Multi-criteria decision analysis: environmental applications and case studies. CRC Press.

Moagar-Poladian, S., Folea, V., \& Paunica, M. (2017). Competitiveness of EU member states in attracting EU funding for research and innovation. ESPERA, 20(2) Retrieved from http://www.ipe.ro/rjef/rjef2_17/rjef2_2017 p150-167.pdf

Puukka J., \& Lagiou, D. .(2017). Spreading Excellence \& Widening Participation in Horizon 2020Analysis of FP participation patterns and research and innovation performance of eligible countriesEuropean Commission, Directorate General for Research and Innovation, Directorate B Open Innovation and Open Science, Unit B5 Spreading Excellence and Widening Participation.

Reillon, V. (2015). Horizon 2020 budget and implementation. A guide to the structure of the programme. Brussels: European Parliamentary Research Service. Retrieved from http://www.europarl.europa.eu/RegData/etudes/IDAN/2015/571312/EPRS_IDA\%282015\%29571312_E N.pdf

Reillon, V. (2017). EU framework programmes for research and innovation: Evolution and key data from FP1 to Horizon 2020 in view of FP9. European Parliamentary Research Service. Retrieved from http://www.europarl.europa.eu/RegData/etudes/IDAN/2017/608697/EPRS_IDA\%282017\%29608697_E N.pdf

Sana, F., \& Stokkink, D. (2014). L'économie circulaire: changement complet de paradigme économique. Pour la Solidarité: Bruxelles, Belgium, 24

SBA Fact Sheet Romania, European Commision Ref. Ares (2017)1735504 - 31/03/2017 http://ec.europa.eu/DocsRoom/documents/22382/attachments/29/translations/

UEFISCDI, Info Day on Policy Instruments under Horizon 2020.(2017),

https://uefiscdi.gov.ro/news-info-day-on-policy-instruments-under-horizon-2020 (accessed on 19 January 2019).

UEFISCDI, Romanian participation in H2020, Bridging the Gap, Science with and for Society, Research Executive Agency, 2017

https://uefiscdi.gov.ro/news-info-day-on-policy-instruments-under-horizon-2020 (accessed on 19 January 2019). 
UEFISCDI, Specific Support to Romania, (2017). Specific Support to Romania Start-ups, Scale-ups and Entrepreneurship in Romania Horizon 2020, Policy Support Facility, https://uefiscdi.gov.ro/newseveniment-de-lansare-a-raportului-start-ups-scale-ups-and-entrepreneurship-in-romania.

Winans, K., Kendall, A., \& Deng, H. (2017). The history and current applications of the circular economy concept. Renewable and Sustainable Energy Reviews, 68, 825-833. 